\title{
DINERO, ABSTRACCIÓN Y CRISIS DE LA SOCIABILIDAD LIBERAL
}

\author{
Eduardo Sabrovsky \\ Universidad Diego Portales
}

\begin{abstract}
RESUMEN: Este ensayo se centra en la situación actual del liberalismo, en un entorno caracterizado por el auge del populismo y por expresiones generalizadas de resentimiento e ira que circulan incesantemente en los medios sociales. Sus tesis principales son: (i) que lo que está en juego en esta nueva era de la ira es el dispositivo moderno de la sociabilidad y la verdad pública en su totalidad, tal como fue inicialmente articulado por Thomas Hobbes y, más adelante, por Immanuel Kant en sus trabajos históricos y políticos, y (ii) que el reto que enfrenta este dispositivo no es efecto de atavismos resultantes de un déficit de modernización, sino del resurgimiento de la inherente insociabilidad de los sujetos modernos, ahora desencadenada por el predominio abrumador de la abstracción en las relaciones sociales. El argumento se inicia con una lectura en profundidad de Lo que el dinero sí puede comprar, libro del intelectual público chileno Carlos Peña, entendido como una pieza destacada del pensamiento liberal contemporáneo, en la cual tanto la potencia de este pensamiento como sus puntos ciegos quedan en evidencia.

Palabras clave: liberalismo, sociabilidad, dinero, abstracción, Kant, Carlos Peña.
\end{abstract}

Eduardo Sabrovsky. Doctor en filosofía, Universidad de Valencia. Profesor titular del Instituto de Filosofía de la Universidad Diego Portales. Email: eduardo.sabrovsky@mail.udp.cl. 


\section{MONEY, ABSTRACTION AND THE CRISIS OF LIBERAL SOCIABILITY}

ABSTRACT: This essay focuses on the present predicament of liberalism in an environment characterised by the rise of populism and widespread expressions of resentment and rage unceasingly circulating in social media. Its main contentions are (i) that what is at stake in this new age of rage is the entire modern apparatus of sociability and public truth, as it was initially articulated by Thomas Hobbes and further on by Emmanuel Kant in his historical and political works, and (ii) that the challenge this apparatus is facing is not result of atavisms that an intensified modernisation would wipe away, but of the emergence of the inherent unsociability of modern subjects, now unbridled by the overwhelming predominance of abstraction in social relations. The argument starts by an in-depth critical reading of the Chilean public intellectual Carlos Peña's book Lo que el dinero sí puede comprar, understood as an outstanding piece of contemporary liberal thought displaying both its pungency and its inherent blind spots.

Keywords: liberalism, sociability, money, abstraction, Kant, Carlos Peña.

\section{Lo que el dinero no puede comprar.}

Lo que el dinero sí puede comprar.

La primera frase titula un libro del filósofo político norteamericano Michael Sandel (con un subtítulo que es una suerte de denominación de origen "made in the USA": Los límites morales del mercado). ${ }^{1}$

La segunda es el libro publicado en 2018 por su antagonista local, el también filósofo político y celebrado intelectual público Carlos Peña González. ${ }^{2}$ Salvo por una breve partícula — "no"; "sí”-, ambos títulos son idénticos, como en un letrero de neón en el que dichas partículas se sucediesen a intervalos fijos. Pero la identidad en cuestión es más profunda. Pues tanto para Sandel, como para Peña se trata de "Lo que...": cosas que el dinero potencialmente podría comprar, con la sola diferencia que Sandel quisiera establecer una suerte de cerco moral, de

${ }^{1}$ Michael J. Sandel, What Money Can't Buy: The Moral Limits of Markets (Nueva York: Farrar, Straus and Giroux, 2013).

${ }^{2}$ Carlos Peña, Lo que el dinero sí puede comprar (Santiago: Taurus, 2017). En adelante, este libro se citará tan sólo con su número de página entre paréntesis. 
modo de impedir que, en el caso de cierto tipo de cosas, lo potencial se transforme en realidad.

Este ensayo pretende profundizar este debate, llevándolo hacia una indagación acerca del dinero, de la abstracción que constituye su esencia y de las consecuencias que se siguen cuando ésta se transforma en el principio rector de la vida moderna en todas sus dimensiones. Por cierto, sería vano e innecesario pretender aquí partir de cero; una revisión de la polémica Sandel-Peña debiera ofrecer, en cambio, un buen punto de partida. Pero aquí las similitudes entre ambos contendientes se desvanecen. El libro de Sandel es rico en información sobre la asombrosa expansión de las cosas que, hoy por hoy, el dinero sí puede comprar; por ejemplo, ciertas prisiones estadounidenses ofrecen a sus huéspedes atractivos upgrades de celda carcelaria, como si se tratase de un hotel o un avión. Pero proporciona poco más; nada, prácticamente que, con menos bombo, no se pueda encontrar en las páginas de un buen reportaje periodístico. Peor aún, su moral es arrojada sobre sus lectores sin fundamento ni discusión; sin consideración alguna, tampoco, de las dinámicas históricas con las cuales se tendría que articular, de modo de hacer realidad su ambiciosa pretensión de poner límites al mercado. Finalmente, todo queda entregado a la voz del evangelizador y la conversión moral de los infieles. ${ }^{3}$ Pero, como espero mostrarlo más adelante a propósito de la tradición de pensamiento que suele identificarse con Immanuel Kant - uno de los muchos nombres que brillan por ausencia en el libro de Sandel; en cambio, Brad Pitt, Zsa Zsa Gabor y Jim Carrey sí tienen su lugar-, cualquier semejanza entre la moralina de Sandel y la reflexión moral de la era moderna es mera coincidencia.

Quedémonos entonces con el libro de Carlos Peña. No hay en él argumentos parroquiales para poner límites a lo que el dinero puede comprar, sino más bien una voluntad de seguir la lógica expansiva del mercado hasta su consumación. En lo que sigue, me propongo aceptar

${ }^{3}$ Sandel es profesor de Harvard. En un sitio web de esa institución (http:// justiceharvard.org/) se lo ve, a todo color y a toda pantalla, como una suerte de predicador evangélico llevando la palabra a audiencias extasiadas que repletan parques, anfiteatros y estadios. Y los eslóganes con que se lo presenta parecen sacados de los más exaltados delirios del advertising: "Un filósofo con el perfil de un rock-star"; "Los mejores diálogos socráticos desde Sócrates" (este último, firmado "Chris Patten, Chancellor of Oxford University”). ¿Estarán aún Harvard y Oxford entre las cosas que el dinero no puede comprar? 
ese desafío, pasando de las cosas que, por su propia naturaleza de cosas, el dinero sí puede comprar, hasta lo que cabría llamar el "ser" del dinero: "ser" que designa no una cualidad misteriosa y "filosófica" del dinero, sino su principio operativo: la abstracción y la cuantificación. Un principio profundamente inscrito en el código genético de la era moderna, que tiene en el dinero su expresión más visible, pero que no se agota en él. ${ }^{4}$ Pues las tecnologías contemporáneas — big data, algoritmización, captura de la atención - hacen posible su propagación hacia la casi totalidad de la vida individual, social y política. El énfasis unilateral, en cambio, en lo que el dinero sí puede comprar desatendiendo, como lo mostraré más adelante, tanto la experiencia histórica del siglo $\mathrm{XX}$ como los inquietantes síntomas del presente, constituye la esencia del paradójico populismo liberal de nuestro tiempo. Éste, al hacer del consumo la forma más elevada de la libertad moderna instala una bomba de alto poder sobre las bases mismas de la legitimidad de los discursos considerados como públicamente verdaderos bajo las condiciones de la moderna democracia liberal. De esta manera, el complejo dispositivo que desde sus orígenes el mundo moderno ha venido produciendo para establecer qué es, y no es, plausible de ser considerado verdadero y legítimo en el espacio público —universidades y demás instituciones formativas, think-tanks, prensa "seria", instituciones culturales en general - queda desactivado, expuesto como arbitrario poder empeñado en reprimir la genuina libertad, la de elección en el mercado. ${ }^{5}$

${ }^{4}$ Para la cuantificación como principio fundante del mundo moderno, ver: Alfred W. Crosby, The Measure of Reality: Quantification and Western Society, 1250-1600 (Cambridge: Cambridge University Press, 1997); Jerry Z. Muller, The Tyranny of Metrics (Princeton: Princeton University Press, 2018).

${ }^{5}$ Es preciso distinguir entre tres tipos de populismo, no obstante que en la realidad se presenten frecuentemente mezclados: 1) Populismo a la manera de Donald Trump: "America first" es la Norteamérica que sueña con muros que la sustraigan de las catástrofes climáticas, migratorias y sociales asociadas al "American way of life" vuelto modelo planetario. 2) Populismo como intento de protección ante las catástrofes desencadenadas por la globalización; asume por lo general la engañosa forma del chovinismo, el racismo, etcétera. 3) "Populismo liberal", que se halla en la base de los dos anteriores. Se caracteriza por privilegiar la abstracción - mercado, cuantificación tecnologizada - por sobre cualquier otra forma de relación entre seres humanos; de este modo, potencia la insociabilidad de base de los individuos modernos. Ver Bruno Latour, Down to Earth: Politics in the New Climatic Regime (Cambridge, UK; Medford, MA: Polity, 2018). 
Comienzo entonces por algunas observaciones sobre Lo que el dinero si puede comprar. Se trata de una obra que, teniendo en vista los debates político-intelectuales en la actual sociedad chilena, aborda la cuestión de la sociabilidad humana en condiciones en que el capitalismo, el dinero y el consumo se han tornado hegemónicos. Y lo hace mediante un erudito recorrido por la compleja historia del problema. Así, son llamados a dar testimonio en sus páginas muchos de los más connotados pensadores del mundo moderno. Hobbes, Hume, Adam Smith, Kant, Hegel, Simmel, Freud, Durkheim, Arendt, Karl Polanyi, Hayek, Heidegger, Schmitt, Luhmann, Baudrillard, Deleuze, por sólo mencionar algunos nombres, figuran en su frondoso índice onomástico. ${ }^{6}$ A la vez, son numerosas las disciplinas — sociología y antropología, filosofía, derecho, economía - cuyas discusiones Carlos Peña recorre e interpreta.

"Este ensayo trata, pues, del lugar que poseen el dinero y el mercado en la sociedad contemporánea", se lee en la introducción del libro. El recorrido descrito de autores y disciplinas es, por tanto, consubstancial a este intento. Pues se trata, para su autor, de complejizar la cuestión, más allá de las simplificaciones fundamentalistas - muy particularmente en el debate local— con que suele ser tratada. Así, escribe:

La estela de incomodidad que producen los procesos de modernización se atribuye así al mercado, al apetito de lucro, a la omnipresencia del dinero, dejándose ver la sugerencia de que si esas cosas aminoraran su presencia en la vida, si estrecharan el papel que cumplen, todo iría mejor, la sociedad estaría más cohesionada y la vida sería más plena (...) Como todas las escatologías, esa idea (lo mismo que su rival, la idea del mercado total) padece el error de creer que en la vida se puede disponer del lado bueno de las cosas y sacudir de una vez por todas lo malo. (12-13)

En su recorrido, Peña muestra $-\mathrm{y}$ éste es quizás su aporte fundamental - que esa incomodidad es parte de la misma existencia moderna. No surgiría entonces del recuerdo reprimido de un paraíso perdido

${ }^{6}$ En contraste, con excepción de una breve referencia a Adam Smith, Sandel no menciona a ninguno de estos autores. Peña, criticando a Sandel, aproxima su crítica al mercado a la de Karl Polanyi. Pero Polanyi tampoco es mencionado por aquél ni tan sólo una vez. 
y pastoral del cual los seres humanos habríamos sido injustamente expulsados, al que podríamos retornar entonces mediante un acto supremo de voluntad política, sino que de la necesaria contraparte de la libertad de los individuos modernos. Individuos arrojados a un mundo en el cual los costos psicosociales de la finitud de la existencia humana no pueden ser ya cargados a la cuenta de la salvación. Se trataría entonces de un malestar que el individuo moderno no debiera impugnar, sino aceptar con madura entereza.

Hasta ahí, todo bien. No obstante, ¿por qué es tan esquiva esa madurez? Como Peña elocuentemente lo describe, en nuestro país, "las multitudes inundan los malls y pasean entre sus vitrinas, anhelantes de las cosas que miran, como si buscaran en ellas algo que supieran de antemano, desde siempre, y que ahora sólo se trataría de encontrar" (43-44). No obstante, ¿ofrece la cultura del consumo la posibilidad de que esas multitudes procesen maduramente el malestar, o las destina a vivirlo como resentimiento? Pues, por alguna razón, sobre la cual es fundamental reflexionar, esas multitudes parecen ser refractarias a esa maduración, y prefieren más bien seguir a predicadores de diversas layas: fugaces superstars académicos "de izquierda" — las comillas son aquí imprescindibles - al estilo de Sandel, o, de un modo más profundo y digno de consideración, políticos populistas y evangelizadores que día a día aumentan su arraigo entre la población, y cuyas prédicas encuentran terreno fértil en el malestar, que es la contracara, el "lado b", de la cultura del mall.

Carlos Peña, evidentemente, no está del lado de los predicadores. Pero tampoco parece hacerse cargo de la misma naturaleza moderna del problema. Pues, dada la frecuente aparición en su libro de la palabra "nostalgia" y otras afines cuando se trata de los críticos de la sociedad de consumo, pareciera que, para él, finalmente, el malestar sería el resultado, no de la propia modernización de todos los ámbitos de la existencia, sino de atavismos que, nuevamente, una buena dosis de economía de mercado podría hacer desaparecer. Con esto, la lectura de su libro produce una fuerte sensación de déjà $v u$ : ya ante la primera "edad de la ira" del siglo $\mathrm{XX},{ }^{7}$ aquella que culminó con el fascismo, el nacionalsocialis-

${ }^{7}$ Para "la edad de la ira", tanto en sus versiones que llamo "primera" como "segunda", ver: Pankaj Mishra, La edad de la ira (Barcelona: Galaxia Gutenberg, 2017). 
mo, el estalinismo y la guerra, la reacción de algunas capas de la intelectualidad fue, simplemente, atribuir todo ello a la barbarie - barbarie germana, barbarie eslava-, exonerando así de responsabilidad a las violentas modernizaciones capitalistas a nivel global. Finalmente, ese recurso de exoneración se trasladó a la cultura de masas: hasta hoy, en gran parte del cine de Hollywood, Hitler, Mussolini, Stalin y sus seguidores suelen ser presentados como bárbaros estrafalarios, de modo que toda consideración seria del asunto queda de antemano bloqueada.

La segunda edad de la ira, la que parece estar en ciernes, suscita reacciones semejantes: la cultura de masas, el cine y los juegos electrónicos, con sus monstruos, extraterrestres y superhéroes, y sus combates del bien contra el mal, son expresiones tanto del malestar como de la tendencia a conjurarlo mediante representaciones simplistas. Y la cultura de los intelectuales, con interpretaciones que, o bien moralizan piadosamente el asunto (à la Sandel), o bien lo intentan archivar bajo el rótulo de la nostalgia, no lo hace tampoco mejor. No obstante, es posible que en los mismos saberes que el libro de Carlos Peña invoca esté contenida una interpretación ni nostálgica ni moralizante de la insociabilidad contemporánea. En lo que sigue, me propongo mostrar que esto es así, y muy particularmente en el caso del pensamiento filosófico moderno al que Peña hace más frecuente referencia, el asociado al nombre de Immanuel Kant. Más precisamente, me propongo profundizar en dos nociones, "autonomía" e "insociable insociabilidad", a las cuales Peña otorga un lugar central en su libro, pero sin advertir al parecer que en ellas — en el problema que en ellas se plasma - podría encontrarse la explicación de los indóciles fenómenos sociales del presente.

"La historia de la filosofía no es un vano museo de distracciones y de juegos verbales", escribió alguna vez Jorge Luis Borges. ${ }^{8}$ Si hay pensador moderno a quien esta observación se aplica plenamente, ése es Kant. Pues Kant fue un agudo observador del mundo moderno; su filosofía no es pieza de museo, sino una muy vigente indagación acerca de los desafíos que enfrenta una sociedad secularizada, cuyos integrantes, en su vida práctica, no se rigen por mandatos trascendentes, sino por la maximización de sus propios intereses egoístas. Son, en la terminología de Kant, que Carlos Peña frecuenta, "insociables". Y el desafío

${ }^{8}$ Jorge Luis Borges, "De las alegorías a las novelas", en Obras completas II, 1952-1972 (Buenos Aires: Emecé, 2004), 122-124. 
consiste en operar la transmutación de esa insociabilidad en sociabilidad; en "insociable sociabilidad", como escribe Kant en uno de sus más célebres aportes a la filosofía de la historia, su Idea para una historia universal en clave cosmopolita. ${ }^{9}$

Mas, antes de entrar a este estrato del pensamiento de Kant, vale la pena detenerse en un concepto que aparece con frecuencia en el libro de Peña que comento: "autonomía". El término, en su acepción kantiana, alude al mayor logro que el mundo moderno ofrecería a los seres humanos: la emancipación de todas las sujeciones "heterónomas"; ya sea la sujeción externa, como la ciega obediencia que los seres humanos prestan a autoridades morales, políticas e intelectuales; o la sujeción interna a las propias pasiones e inclinaciones, que tienden a encerrar al individuo en su propia insociabilidad, y cuya relevancia se acrecienta a medida que la misma dinámica de la vida moderna desencadena la emancipación práctica respecto al primer tipo de sujeción, desde los poderes señoriales y religiosos hasta llegar a todo tipo de autoridad externa. La cuestión que examino aquí es si acaso esa autonomía equivale a libertad de elección, como la que los consumidores ejercen en el mercado. El examen se justifica, dado que esa equivalencia es un elemento fundamental del planteamiento de Carlos Peña.

Por cierto, no faltan en él afirmaciones condicionales y prudentes. Así, por ejemplo:

La autonomía personal y la libertad de configurar la propia vida, así como la libertad política, muestra una larga experiencia, dependen en parte importante de la existencia del intercambio más o menos libre y de la expansión del consumo. (13)

Si ésta es una "parte importante" - difícil no coincidir en ellorestaría, sin embargo, por saber cuál sería la parte menos o no importante de la cual implícitamente se distingue, y de qué manera se establecen esas distinciones y su valoración. El autor, sin embargo, deja esto sin explicar. De este modo, más adelante en su libro, la identificación entre autonomía y mercado se vuelve total. Así, ya casi finalizando su recorrido, se lee en él:

${ }^{9}$ Immanuel Kant, Idea para una historia universal en clave cosmopolita (México, DF: UNAM, 2006). 
El mercado no posee una idea antecedente de virtud o de vida buena que promover (aunque subyace en él la idea de que la mejor vida es la vivida autónomamente), sino que él se orienta por las preferencias, deseos y anhelos de las personas sin someterlos a control ni dirección moral alguna. De ahí que los precios en un mercado no reflejen el valor intrínseco de las cosas, sino que se trata nada más que de un índice acerca de cuáles son, y qué tan intensas, las preferencias de la gente. (224, los énfasis son míos)

No obstante, la construcción conceptual de Kant, tal como termina de ser elaborada en su célebre texto La religión dentro de los límites de la mera razón (1793), se centra en la idea de que dirección moral y autonomía no solamente no se contraponen, sino que conjugarlas es imprescindible para la deseada transmutación de insociabilidad en sociabilidad. La sociabilidad moderna supone que los individuos no sólo se han liberado del yugo de la tradición, sino que son capaces también de extraer de sí mismos los recursos morales (psíquicos, diríamos en términos más contemporáneos) que les posibilitarían ejercer un control sobre sus propias inclinaciones y pasiones sin tener que recurrir a autoridades externas.

El naciente mundo moderno se levanta sobre las ruinas del mundo medieval; al disolverse la totalidad ética al interior de la cual el fiel cristiano vivía, la obediencia a la tradición que formaba parte de ésta no pudo sino transformarse en mera obediencia externa; como lo entendieron ya los reformadores protestantes, a partir de entonces no hay más fuente de recursos éticos, ni de sentido para la vida social y política, que aquella que emana de la propia vida del individuo. Pero - y esto es fundamental - tanto los teólogos de la Reforma como Kant entienden que no se trata de esa vida sin más: no se trata de dar rienda suelta a los impulsos, a las egoístas pasiones instantáneas de los individuos, sino de hacer posible su postergación en la perspectiva de la apertura hacia un futuro en común con otros; en suma, de hacer del humano, así lo observará Nietzsche en su Genealogía de la moral, "un animal al que le sea lícito prometer". ${ }^{10}$ Pero en Kant, y en eso consiste su genio, no se trata de legitimar una nueva imposición venida desde el exterior (ése había

${ }^{10}$ Friedrich Nietzsche, La genealogía de la moral. Un escrito polémico (Madrid: Alianza, 2013), tratado 2, §1 (itálicas de Nietzsche). 
sido el destino del calvinismo y de sus sucesores puritanos), sino de la autoproducción de una instancia interior, psíquica, capaz de poner la energía de esos mismos impulsos y pasiones al servicio de la indispensable sociabilidad.

La instancia en cuestión es la razón, que Kant entiende como sede de directivas incondicionales (la palabra alemana para incondicional, Unbedingen, lo dice todo: Ding equivale a cosa; lo incondicional es lo no cósico, lo des-cosificado) y coincidentes con la voz interior más propia de todos y de cada uno de los individuos modernos. Y la autonomía kantiana es inseparable de este momento de incondicionalidad, que se contrapone radicalmente a toda apología de la mera libertad de elección en medio de las cosas. Pues esa mera libertad, tomada por sí sola, vuelve sordos a los individuos al llamado de esa voz interior.

Pero sólo un puritano podría pretender que la voluntad humana se podría regir, así sin más, por mandamientos incondicionales. Por ello Kant complejiza la cuestión, distinguiendo entre dos aspectos de la voluntad, que designa mediante variantes que la lengua alemana hace posibles. Por una parte, Wille, la voluntad como legisladora, como sede de la ley moral en todo su rigor racional e incondicional y en su plena capacidad de abrirse paso a través de los caparazones egoístas de los individuos; por la otra, Willkür, o sea, la voluntad como capacidad de acción, de elección en un mundo secular. ${ }^{11}$ Esta última es esa "parte importante" de la construcción kantiana de la autonomía, que el profesor Peña reconoce. Pero no es más que una parte. Hay libertad de elección, sin duda, pero también hay ley moral incondicional. ¿Cómo se resuelve esta contradicción?

En La religión dentro de los límites de la mera razón, Kant termina por dar respuesta a esta pregunta. ${ }^{12}$ No hay solución fácil al conflicto

${ }^{11}$ Para una discusión de estos dos aspectos, ver: Eduardo Chapernel Elorduy, "Gesinnung y autoconocimiento en la filosofía de la religión kantiana", en Rostros de la razón: Immanuel Kant desde Hispanoamérica. Vol. III Filosofía de la religión, de la historia y Crítica de la facultad de juzgar: Estética y teología, editado por Gustavo Leyva (Barcelona - Ciudad de México: Anthropos, 2014); Henry E. Allison, "Wille, Willkür, and Gesinnung", en Kant's Theory of Freedom (Cambridge: Cambridge University Press, 1990), 129-45, y Richard J. Bernstein, Radical Evil: A Philosophical Interrogation (Cambridge, MA: Polity, 2002).

12 Immanuel Kant, La religión dentro de los límites de la mera razón (Madrid: Alianza, 2009). 
entre Wille y Willkür; como en el psicoanálisis, que de alguna manera la elaboración de Kant anticipa, no queda más que aceptar el desgarro inherente a la psiquis moderna. Ahora bien, el teatro de este conflicto es aquello que Kant llama “disposición” (Gesinnung), la cual, no obstante estar compuesta de los rasgos hereditarios y de las experiencias vitales del individuo, es la más elevada expresión de su autonomía, a condición de que éste la reconozca como el producto de su propia elección voluntaria. ¿Pero cómo es posible pretender que la herencia, la biografía, que se encuentran en el pasado, sean asumidas como realizaciones de la voluntad? ¿No estaba acaso Kant ya senil, se preguntan algunos lectores, cuando se le ocurrió esto? Pero, si la autonomía ha de tener algún contenido, algún significado relevante para la vida real, éste ha de consistir, no en la libertad de elegir esto o lo otro, esta cosa o esta otra cosa, sino en elegirse des-cosificada, incondicional y soberanamente a sí mismo; finalmente, sólo esta elección existencial salva a la Willkür kantiana de disolverse en mera aquiescencia ante la seducción que emana de las cosas y, más concretamente, de las mercancías. ${ }^{13}$

En esto, como en muchas otras cosas, Kant es precursor de Nietzsche y de su crítica radical a la moral del resentimiento, la moral de quienes no están en condiciones de liberarse del peso de su historia asumiéndola como propia. En obras como La gaya ciencia y Ecce Homo, Nietzsche elabora una versión depurada de la autonomía kantiana, a la cual llama, muy apropiadamente, amor fati, "amor al propio destino". Escribe, y sus claras palabras arrojan luz sobre lo que quedaba oscuro en la elaboración de su antecesor:

Mi fórmula para expresar la grandeza en el hombre es amor fati: el no querer que nada sea distinto ni en el pasado ni en el futuro ni por toda la eternidad. No sólo soportar lo necesario, y aún menos disimularlo — todo idealismo es mendacidad frente a lo necesario- sino amarlo... ${ }^{14}$

Tanto Kant como Nietzsche advierten, además, que la construcción moral autónoma está siempre en riesgo de fracasar; en la terminología

${ }^{13}$ Ibídem, 29-34.

${ }^{14}$ Friedrich Nietzsche, Ecce homo: Cómo se llega a ser lo que se es (Madrid: Alianza Editorial, 2013), 71 (itálicas de Nietzsche). 
del primero, la "disposición" puede colapsar, quedando reducida a mera "propensión" (Hang) que Kant, en una quizás profética nota al pie de su Religión dentro de los límites de la mera razón, asocia a la adicción a las substancias intoxicantes. ${ }^{15} \mathrm{Y}$ si bien esta asociación podría parecer algo extrema — ¿pero lo es, realmente, aquí y ahora? — ${ }^{16}$ ya es posible extraer de todo esto un corolario relevante para un diagnóstico del presente: de faltar las condiciones para que el sujeto realice su autonomía en este sentido fundamental —en cuanto decisión moral radical- el resentimiento ocuparía su lugar, como disposición psíquica predominante de la vida moderna.

Vuelvo sobre esto más adelante. Me interesa ahora examinar cuáles son los requerimientos que Kant, en su filosofía de la historia, establece para que la primordial insociabilidad moderna se transmute efectivamente en sociabilidad. Como Carlos Peña lo hace ver en su libro, Kant no añora el pasado premoderno; por el contrario, ve en la insociabilidad moderna el motor capaz de poner en tensión las fuerzas de los sujetos y extraerlos de "una arcádica vida de pastores", en la cual no son distintos de los borregos a su cuidado; de impulsarlos a "llenar el vacío de la creación". Pero, nuevamente, la descripción que el autor hace en su libro es parcial e insuficiente (34-35). Pues en el texto al que hace referencia - el mencionado Idea para una historia universal en clave cosmopolita - la transmutación insociabilidad-sociabilidad no tiene nada de automático, sino que pende de una compleja y frágil premisa: la postulación de una teleología de la naturaleza y de la historia humana; esto es, de un desenlace que aseguraría que, en medio de sus a veces catastróficos y desalentadores episodios, la especie humana estaría de alguna manera encaminada a un destino de plenitud.

Observemos el texto de Kant más de cerca. ${ }^{17}$ Idea para una historia universal en clave cosmopolita está organizado como una secuencia

${ }^{15}$ Kant, La religión..., 37, nota 9.

${ }^{16}$ Ver, por ejemplo, Adam Alter, Irresistible: The Rise of Addictive Technology and the Business of Keeping Us Hooked (Nueva York: Penguin Books, 2018). La etimología de "adicción" es sugerente: esclavitud. Ver Valentín Anders y múltiples autores, en http://etimologias.dechile.net/.

${ }^{17}$ Para un análisis de los distintos aspectos de este texto de Kant, ver Kant's Idea for a Universal History with a Cosmopolitan Aim: A Critical Guide, editado por Amélie Oksenberg Rorty y James Schmidt (Cambridge, New York, Melbourne: Cambridge University Press, 2012). 
de principios, desde un primero que postula que "[t]odas las disposiciones naturales de una criatura están destinadas a desarrollarse alguna vez de manera completa y adecuada", ${ }^{18}$ hasta el octavo, que dice: "Se puede considerar la historia de la especie humana en su conjunto como la ejecución de un secreto plan de la naturaleza (...)". ${ }^{19}$ De nuevo, ¿estaba Kant en sus cabales cuando, contra lo enseñado en su Crítica de la razón pura, pretende ahora que aceptemos la idea de una naturaleza que velaría secretamente por el destino de la humanidad? Pero las cosas son más complejas.

En 1790, Kant publica su tercera y última Crítica, la Crítica de la facultad de juzgar. ${ }^{20}$ Observa allí que nuestra aproximación cognitiva a la naturaleza consiste, en su mayor parte, no en la aplicación a los fenómenos de conceptos preexistentes (de eso se había ocupado en Crítica de la razón pura), sino en producir conceptos de modo inductivo, "reflexionante" lo llama, a partir de datos empíricos carentes en sí mismo de organización. Es decir, la cognición se sustenta en el implícito supuesto de una primordial afinidad ("conmensurabilidad", escribe Kant) entre nuestras facultades cognitivas y la realidad exterior. El placer estético, la belleza parecerían confirmar esta conmensurabilidad $\mathrm{y}$, con ella, la posibilidad de reconciliar al ser humano con la naturaleza, tanto exterior como interior. No obstante, se trata de vivencias que no logran trascender la subjetividad. Más en profundidad — de esto trata la segunda parte de esta tercera Crítica-, se requeriría de una teleología de la naturaleza capaz de garantizar que, en su moderna autoafirmación política, tecnocientífica, moral, la humanidad moderna no sería un mero episodio efímero, carente de legitimidad y destinado a conducir a la humanidad a la catástrofe, sino el resultado de una finalidad de alguna manera inscrita en la misma naturaleza. Pero, para el autor de la Crítica de la razón pura, aseverar algo así necesariamente desborda los límites de la razón entendida en términos modernos. Por ello, finalmente, no podría sino tratarse de un postulado; de una suerte de ficción performativa — hagamos como si tal finalidad trascendente existiese - como contenido de esa religión minimalista, la kantiana "religión en los límites de la

\footnotetext{
${ }^{18}$ Kant, Idea para una historia..., 37.

${ }^{19}$ Ibídem, 56.

${ }^{20}$ Immanuel Kant, Crítica de la facultad de juzgar (Caracas: Monte Ávila
} Editores, s/f). 
mera razón". Una religión, es decir, no un mero juego intelectual, sino una fe racional y a la vez colectiva. ${ }^{21}$

Estas ideas, desarrolladas en detalle en 1790, estaban ya presentes en el escrito de 1784. De hecho, a los ocho principios mencionados, Kant agrega un noveno, en el cual se desdobla en atento lector de los principios anteriores, y observa: "Parece una ocurrencia un poco extraña y hasta incongruente tratar de concebir una historia con arreglo a cómo debía marchar el mundo si se atuviera a ciertas finalidades razonables: parece que el resultado sería algo así como una novela". ${ }^{22}$ Pero entonces, ¿por qué escribirla? "Esa idea podría ser útil", responde de inmediato Kant. Mas, ¿útil para qué? Aunque a grandes rasgos conocemos la respuesta, vale la pena emular a Kant en la lectura atenta de su texto. Pues todo él está marcado por la amenaza de la catástrofe que se desencadenaría sobre la humanidad si esas "finalidades razonables" no se cumpliesen: la arbitrariedad, el desconsuelo, la sospecha, la envidia corrosiva, la tiranía son las plagas letales que Kant enumera.

En suma: sin teleología, la primordial insociabilidad difícilmente podría transmutarse en sociabilidad. Y, si a nosotros, secularizados lectores, se nos hace difícil aceptar esta teleología, tampoco es razonable atribuir a Kant la fe ingenua de la cual nosotros nos hemos despojado. Más bien, Kant nos ha dejado una advertencia: si el mundo moderno no fuese capaz de extraer de sí mismo una suerte de religión civil, en la cual los individuos renueven su compromiso con el proyecto moderno, proporcionando así un sostén a la producción de subjetividades autónomas en el sentido moral ya descrito, entonces los espectros mencionados más arriba se dejarán caer sobre él: ${ }^{23}$ arbitrariedad, desconsuelo, sospecha, envidia, tiranía. ¿Suena conocido?

${ }^{21}$ Para la filosofía del "como si" (als $\left.o b\right)$ en Kant y en Nietzsche, ver Hans Vaihinger, Die Philosophie des Als Ob: System der theoretischen, praktischen und religiösen Fiktionen der Menschheit auf Grund eines idealistischen Positivismus, editado por Alfred Schilken (CreateSpace Independent Publishing Platform, 2014).

${ }^{22}$ Kant, Idea para una historia ..., 60.

${ }^{23}$ La idea de un "estado de naturaleza ético" y de la formación que los individuos requieren para salir de él son parte fundamental de la religión cívica de Kant. En la tercera parte, primera sección, "Del estado de naturaleza ético", Kant escribe: "Un estado civil de derecho (político) es la relación de los hombres entre sí en cuanto están comunitariamente bajo leyes de derecho públicas (que son en su totalidad leyes de coacción). Un estado civil ético es aquel en el que los hombres están unidos bajo leyes no coactivas, esto es: bajo meras leyes de virtud". Kant, $L a$ religión dentro..., 95. 
En el capítulo que Carlos Peña dedica a discutir expresamente el libro de Sandel, su insuficiente consideración de este fundamental aspecto de la cuestión se expresa con nitidez. Escribe Peña:

Un intercambio en estado de necesidad (cuando usted contrata para salvar un bien que juzga más importante que el precio que sacrifica) es injusto, pero es voluntario... Una persona pobre que celebra un contrato quiere celebrarlo; decir que las circunstancias lo obligan es una forma figurada de describir el fenómeno que no ayuda a su comprensión intelectual (...) no se observa qué ventaja se sigue de llamar falta de voluntad a la injusticia. Una cosa es no querer hacer algo, otra cosa es ser víctima de la injusticia. $(118-120)$

Para establecer esto - es decir, la compatibilidad entre coacción externa y libre voluntad en el caso de "una persona pobre"- Peña acude a Puffendorf, a Pothier, al mismísimo Aristóteles. Pero, para quien haya seguido mi argumentación en las páginas anteriores, la falacia argumentativa que hay aquí debiera ser evidente. Pues, ciertamente al interior de la Gesinnung, de la disposición libremente elegida por un sujeto moderno en plena posesión de sí mismo, la injusticia no es falta de voluntad, sino más bien la ocasión de su ejercicio: el sujeto, una vez sublimada la coerción externa, se torna nietzscheanamente capaz de hacer válida su promesa, cumpliendo, contra viento y marea, lo establecido en el contrato que ha celebrado. Pero todo esto supone precisamente lo que Carlos Peña ha omitido; es decir, que la voluntad moral, a la cual apela, no se reduce a mera insociable libertad de elección, y que ello sólo es posible para individuos cuya formación moral les hace posible transmutar su inherente insociabilidad en sociabilidad. Si no se dan esas condiciones, no es posible pretender que "una persona pobre que celebra un contrato quiere celebrarlo"; a la vez, se hace evidente que esa pretensión será vivida por el pobre mismo como imposición injusta, e internalizada como ira y resentimiento.

Más allá de su problemática comprensión de la cuestión de la insociable sociabilidad, de la moral y de la filosofía de la historia de Kant, 
y de su alcance respecto a los problemas de la vida contemporánea, hay un rasgo del mundo moderno que Lo que el dinero sí puede comprar destaca, y que merece ser comentado en profundidad, en la perspectiva de ir hacia la respuesta a nuestras preguntas iniciales: ¿qué es el dinero?, ¿cómo llega la abstracción a ser el principio organizador fundamental de la vida moderna, y qué consecuencias se seguirían de esto? Se trata de la relación entre abstracción y libertad, tal como fue observada, entre otros, por Georg Simmel en su Filosofía del dinero; ${ }^{24}$ más concretamente, entre autonomía individual, en el sentido elaborado más arriba, y los modernos dispositivos de abstracción que, de manera creciente, sustituyen a las relaciones humanas tradicionales; del dinero en cuanto "equivalente universal"; más en general, agrego, de las tecnologías de la cuantificación que, partiendo desde las sencillas técnicas contables del siglo XIV, han terminado por ser un elemento principal del paisaje sociopolítico contemporáneo. Escribe al respecto Carlos Peña:

[E]n la economía moderna (que para Simmel es el intercambio de mercado mediado por el dinero) los sujetos dependen, en casi todas las dimensiones de su vida, de un intercambio con otras personas; pero ese intercambio, mediado por el dinero, exige, por decirlo así, poco gasto comunicativo de manera que deja fuera de la relación a la personalidad. De esta forma, sostiene, se produce "la independencia interior y el sentimiento del para sí individual (...) en el cambio voluntario de los sujetos, ocasionado a través de la estructura de la relación, se revela aquella indiferencia del elemento subjetivo, que lleva el sentimiento de la libertad". $(209)^{25}$

Por cierto, Peña tiene razón; nuevamente, sin embargo, su razón no es toda la razón. El dinero hace posible un frecuentemente bienvenido ahorro comunicativo: no tengo que trabar amistad con el gásfiter para que haga reparaciones en mi domicilio, ni con el panadero para que me venda pan; para que el taxista evangélico me transporte basta con que le cancele la tarifa indicada en el taxímetro, no que comparta sus lecturas

${ }^{24}$ Georg Simmel, Filosofía del dinero (Madrid: Universidad Autónoma de México, 2013).

${ }^{25}$ Peña está citando Filosofía del dinero. 
de la Biblia, etcétera. Y no se trata sólo del dinero, sino del principio que encarna: la cuantificación y, más precisamente, la abstracción.

En virtud de ella, el trabajador puede, en principio, prescindir de servilismos tradicionales hacia jefes y patrones; en principio, nada impide que un militante de un partido antisistema trabaje bajo las órdenes de superiores pertenecientes, digamos, al Opus Dei. Y si bien fácticamente, al menos en sociedades como la chilena, algo así podría ser de difícil ocurrencia, la tendencia es indiscutible: las organizaciones obstinadas en discriminar ideológicamente a su personal terminarán, muy probablemente, sucumbiendo bajo el peso de una fuerza de trabajo devotamente ineficiente.

Pero esta consumada libertad negativa tiene costos. Carlos Peña no los desconoce. Escribe:

El surgimiento de una economía estrictamente monetaria, advirtió Simmel, favoreció las interacciones humanas en un muy alto nivel de abstracción, con un mínimo de esfuerzo comunicativo (...). Pero es fácil advertir que, al mismo tiempo, el uso del dinero se convierte en un formidable destructor de las relaciones comunicativas tradicionales. El dinero, al no necesitar del mundo de la vida, por el nivel de abstracción que supone, corroe las tradiciones y formas de existencia en las que el individuo estaba emboscado y protegido y permite que, desprovisto de esas referencias que lo abrigaban, deba ahora salir desnudo a la luz. (21-22)

Las relaciones abstractas, efectivamente, no quedan encerradas en sus ámbitos de origen. Del mundo de la producción y circulación mercantil, así como del trabajo, en el cual se tornan primeramente dominantes, ellas saltan hacia el mundo de las interacciones comunicativas que conforman lo que una importante vertiente de la filosofía del siglo XX, la fenomenología, suele llamar "mundo de la vida". ¿Qué sucede entonces? ¿Y qué significa esa cuasi mística expresión de Peña: "salir desnudo a la luz"?

Pues pocas líneas más atrás ha escrito, en relación con el mismo proceso, que oculta al "sujeto que usted es". La luz en cuestión, entonces, no descubre, sino oculta; la desnudez no alude a la plena presencia de una vida humana, sino más bien a lo que resta de ella bajo la radiación intensa de la abstracción. Y ese residuo — difícil no pensarlo- es 
un "hombre sin atributos", como el personaje de la novela homónima de Robert Musil, contemporáneo de muchos de los pensadores convocados por Peña en su argumento. No obstante, como las mil y tantas páginas de la novela de Musil lo evidencian, Ulrich, su "hombre sin atributos", no es un consumidor vagando en el laberinto del mall comercial, sino un refinado matemático e intelectual vienés de comienzos del siglo XX, dotado de recursos espirituales $-\mathrm{y}$ materiales también, por cierto- que le hacen posible procesar su confinamiento interior mediante la distancia y la ironía, y lo libran de quedar atrapado en la insociabilidad y el resentimiento.

Pero en la novela de Musil, a la figura de Ulrich se contrapone sugerentemente la de Moosbrugger, asesino serial que aterra y fascina a los buenos burgueses de Viena. “A ojos del juez”, reflexiona Ulrich después de observarlo en la sala del tribunal que lo juzga, "Moosbrugger era el origen de sus actos; a los de Moosbrugger, éstos se habían posado sobre él, cual pájaros que hubiesen aparecido volando no se sabe de dónde". ${ }^{26}$ Más allá, y por sobre sus crímenes, lo que define entonces a Moosbrugger es la incapacidad de aceptarse a sí mismo como "origen de sus actos"; esa incapacidad lo transforma en el paradigma del resentimiento. Bajo la radiación intensa de la abstracción, entonces, la vida desnuda se desdobla: sobre Ulrich, matemático, y por ello predispuesto a la abstracción, ésta fluye como la radiación benéfica de un solárium; sobre Moosbrugger, en cambio, cae como rayos desde un cielo hostil.

Como otras grandes creaciones literarias de ese tiempo (La montaña mágica, de Thomas Mann; La conciencia de Zeno, de Italo Svevo, por sólo nombrar un par), la novela de Musil transcurre en una suerte de estado de suspensión. Pues, cuando el tiempo nuevamente se ponga en marcha, la época no será ya la de Ulrich en su civilizada Viena, sino la de los Moosbrugger, matando y muriendo en los campos de batalla de la Gran Guerra, o incorporándose a la inmensa oleada de ira y resentimiento que se dejará caer sobre Europa y buena parte del planeta en las décadas siguientes.

La generación de Musil, de Freud, Durkheim, Simmel y tantos otros fue testigo de estos cataclismos, difícilmente disociables de la expansión de la lógica de la abstracción y de su concomitante insociabili-

${ }^{26}$ Robert Musil, Der Mann Ohne Eigenschaften (Hamburg: Rowohlt Verlag, 1952), 77 (la traducción es mía). 
dad. El siglo XX no fue solamente el del consumo, sino el de la ira y el resentimiento; el de las guerras y las revoluciones; el de Hitler y Mussolini; Lenin, Stalin, Mao; del fascismo y bolchevismo como expresiones del malestar intenso y generalizado de la época. Las multitudes no se limitan a consumir mansamente; matan y mueren en los campos de batalla; asaltan el Palacio de Invierno; desfilan con antorchas y esvásticas en Nuremberg.

Una frondosa literatura registra la reacción de la intelectualidad de la época frente a estos fenómenos: Durkheim y su anomia, Weber y su desencanto, Adorno y la alienación, Husserl y la "crisis de la humanidad europea". Y no se trata, en ellos, de suave nostalgia de salón, sino de puesta en juego, activación, interrogación urgente del patrimonio intelectual, filosófico-político de la edad moderna ante la aterradora explosión de insociabilidad de la cual les tocó ser testigos. Y si bien el posterior triunfo de las democracias liberales que culminó con el colapso de los "socialismos reales" ha podido llevar a pensar que la explosión de entonces fue un mero episodio pasajero, las mismas nociones que he desplegado aquí lo desmienten. Pues lo que entró ya entonces en crisis fue el dispositivo mismo de la sociabilidad moderna: el crisol alquímico que se suponía capaz de transmutar insociabilidad en sociabilidad. Más concretamente, de transformar la dispersa y egocéntrica subjetividad de los individuos modernos en madura disposición; de erradicar las plagas de la historia - arbitrariedad, desconsuelo, sospecha, envidia, tiranía - haciendo de ésta una "historia universal en sentido cosmopolita"; de conducir la racionalidad utilitaria, limitada y egoísta, hacia una religión racional del progreso.

Vuelvo a la cuestión del mercado, la abstracción y el ahorro comunicativo. Como los ejemplos dados más atrás sugieren, el ahorro comunicativo es pertinente cuando se trata de proveedores de bienes o servicios - panaderos, gasfíteres, taxistas, más un largo y creciente etcétera-, con los cuales la economía de mercado ha hecho progresivamente posible sostener relaciones que eximen a los individuos de ir más allá de su inherente insociabilidad. Así, mercado, abstracción, dinero son, primordialmente, tecnologías de la insociabilidad; reproducen por una parte la insociabilidad ubicada en el mismo código genético del mundo moderno; a la vez, la potencian y la proyectan más allá, tanto en extensión — hacia la planetarización del capitalismo - como en pro- 
fundidad, hacia la propia psiquis del ser humano. Veamos esto más en detalle.

Con su ahorro comunicativo, el dinero es el elemento central de lo que cabría llamar "dispositivo social de la confianza". No se trata aquí de la confianza substantiva entre integrantes de una familia o comunidad, sino de la confianza formal, institucionalizada y tecnologizada hasta constituir un complejo dispositivo, que caracteriza y hace posible al capitalismo moderno. ¿Cómo puede un productor de papas, digamos, en Chiloé, tener la certeza de que, si vende sus papas a un mayorista europeo, podrá adquirir, a su vez, por ejemplo, un vehículo "cuatro por cuatro" de último modelo fabricado en China? La solución está, por cierto, en el dinero; en el dinero como mediador, a través del cual se hace presente la complejidad de la estructura social y económica en medio de la cual se realiza tal mediación. Es decir, el dinero no es mero dinero: se trata, más bien, del elemento en el cual se condensa una estructura fundamental: el dispositivo societal de la confianza, que abarca todas las esferas de la sociedad moderna, desde las instituciones de la banca, del derecho y el Estado, hasta la educación y la cultura. Ahora bien: la confianza hecha dispositivo tiene su base en la cuantificación. Esta cuantificación, entonces, es un imperativo central de la era moderna, que abarca desde las sencillas prácticas y técnicas contables en las que parece haber tenido su origen, hasta las complejas matemáticas tanto de las finanzas como de la ciencia. ${ }^{27}$

El ahorro comunicativo es inseparable del proceso histórico del surgimiento, expansión e intensificación de este imperativo, hasta llegar a la sociedad masificada y global de nuestros días. No se trata entonces de una tendencia inscrita en la naturaleza humana, sino de la más poderosa tecnología moderna de reducción de la complejidad; su poder

${ }^{27}$ Por cierto, como el mismo ejemplo lo sugiere, hay algo más que dinero en su acepción más inmediata en todo esto: tecnologías del transporte, que posibilitan el acceso a mercados distantes, y, muy decisivamente, tecnologías de comunicación y de cálculo: computadores de enormes capacidades a bajo precio, softwares. La llamada "hoja de cálculo" surgió hace ya casi cuatro décadas con el programa VisiCalc (1979) y, junto a otras killer apps como el software de procesamiento de texto, fue determinante para el crecimiento explosivo de la computación personal antes de internet. Estas tecnologías han sido el motor de la progresiva "capilarización" de la economía de mercado: pequeños productores, en lugares apartados, han podido y han sido incentivados a abandonar la tradicional economía de subsistencia para incorporar sus productos al mercado global. 
la torna omnipresente y por ende invisible, hasta transformarla en una suerte de "segunda naturaleza", cuyo carácter histórico tiende entonces a pasar desapercibido.

Ahora bien, la cuantificación tecnologizada lleva esa reducción al extremo. La matemática reduce las formas del mundo circundante a rectángulos, círculos y curvas resultantes de una cierta función; la técnica hace de esta reducción el principio de la producción de bienes de consumo masivo. Pero, más fundamentalmente, lo que la cuantificación tecnologizada viene haciendo posible ya hace algunas décadas es la transformación de la economía del trabajo en lo que una ya extensa literatura llama "economía de la atención". ${ }^{28}$ Con ella se abre un nuevo y quizás decisivo capítulo de la desnuda vida moderna.

Ya en la primera mitad del siglo XIX, los editores de los grandes periódicos empezaron a caer en cuenta de que su negocio consistía en vender, no información impresa a sus lectores, sino la capacidad de atención de estos a sus avisadores. Surgía así el marketing, cuya penetración, ubicuidad e intensidad las tecnologías digitales contemporáneas han incrementado asombrosamente. Todo proceso económico es, finalmente, una forma de organización de la vida humana, de la cual necesariamente ha de extraer su energía. Pero con la revolución tecnológica contemporánea, la economía capitalista deja de ser la economía de la valorización del trabajo del siglo XIX. Se transforma en "economía de la atención": la atención, es decir, la misma psiquis humana, pasa a constituir el recurso fundamental a poner en valor en el proceso económico. De esta manera, la atención de los individuos es permanentemente solicitada; la enorme huella digital que cada uno de nosotros va dejando en la ahora "internetizada" vida cotidiana hace posible segmentar las audiencias con un grado de exactitud que minimiza todo desperdicio de la atención y maximiza su valorización a través de la información y el avisaje segmentados; finalmente, los públicos segmentados son confinados en grupos de interés cuya afinidad, algorítmicamente producida y reproducida, los transforma en cámaras de eco, en las cuales verdades y hechos alternativos cristalizan a fuerza de clausura y repetición. En estas condiciones difícilmente pueden ya los individuos volverse

${ }^{28}$ Tim Wu, The Attention Merchants: The Epic Scramble to Get Inside Our Heads (Nueva York: Vintage, 2016). Ésta es sólo una pieza en una ya vasta literatura que no puedo detallar aquí. 
reflexivamente sobre sí mismos de modo de asumir, kantiana o nietzscheanamente, su propia disposición, su propio destino. La "sociedad de masas", tan deseada o tan temida, se hace realidad ahora bajo el régimen de las "redes sociales", que transmiten la radiación intensa de la abstracción no sólo hacia todos los rincones del planeta, sino que también hacia la interioridad de los sujetos, instaurando una temporalidad que no admite pausa ni reflexión.

En otras palabras, la sociedad internetizada es también la sociedad en la que el ahorro comunicativo y su concomitante insociabilidad desbordan la esfera tradicional del mercado, hasta invadir todos los ámbitos de la vida intersubjetiva y psíquica. La transformación de la insociabilidad en sociabilidad, ya lo sabemos, no es la operación automática que algunos teóricos del liberalismo, olvidando las enseñanzas de la misma tradición de pensamiento que invocan, han dado en imaginar. Pero los legendarios emprendedores de las tecnologías de la información y la comunicación, como Steve Jobs o Bill Gates, al crear un medio capaz de materializar esas ilusiones, las han expuesto a la severa prueba de la realidad. Y el resultado está a la vista: la insociabilidad se reproduce y circula a raudales a lo largo y lo ancho de la red; a través de ella, legiones de neo-Moosbruggers ventilan a toda hora su ira y su resentimiento; finalmente, la proliferación de verdades, identidades y hechos alternativos contribuye a la deslegitimación de los dispositivos liberales del saber y de la verdad, creando las condiciones para el populismo fascistoide que hoy por hoy perturba seriamente a la Europa liberal, y que con Donald Trump ocupa ya el poder ejecutivo de la nación más poderosa del planeta. ${ }^{29}$

$* * * *$

${ }^{29}$ Agréguese a todo esto que la promesa de la expansión sin límites del "imperio de las cosas" no parece sustentable, ni en términos medio-ambientales ni energéticos. Ver Frank Trentmann, Empire of Things: How We Became a World of Consumers, from the Fifteenth Century to the Twenty-First (Nueva York: Harper, 2016). A la vez, sin el colonialismo, con su violenta destrucción de economías de subsistencia para sustituirlas por plantaciones e industrias extractivas, el moderno capitalismo difícilmente habría llegado a tener el éxito que conocemos. El resultado es esa serie de inquietantes fenómenos contemporáneos — terrorismo, crisis de los refugiados, migraciones masivas - que, en conjunto con las reacciones internas que gatillan, constituyen el retorno de una historia dolorosa, cuya memoria ha sido reprimida, y que ahora vuelve, como un espectro, a golpear la puerta y a poner en escena sus horrores en el corazón mismo de la metrópolis. 
Así, con el ahorro comunicativo y la abstracción, la insociabilidad penetra hasta el núcleo más interno de la sociabilidad liberal: el dispositivo de producción de la verdad pública, cuyos elementos fueron lúcidamente articulados por Thomas Hobbes hace ya más de 350 años. Este aspecto central del pensamiento de Hobbes suele pasar desapercibido, eclipsado tras su reputación como pensador de la política y del derecho. Pero para Hobbes, política y producción de verdad pública son asuntos inseparables. Su "estado de naturaleza" es la moderna insociabilidad en su estado primigenio: en él se enfrentan, en una potencial "guerra de todos contra todos", los individuos que la descomposición del orden medieval ha dejado a la deriva, luego de que - Reforma Protestante de por medio - han aprendido a confiar, no ya en la institución medieval de la verdad, sino en sus propias y subjetivas certezas. ${ }^{30} \mathrm{Y}$ si bien la subjetividad en cuanto árbitro último de la verdad puede dar lugar al escepticismo razonable de un Montaigne, o a la fuga del mundo del pietismo, también, como Hobbes lo observó en su tiempo, hace posible la aparición de la insociable figura del "entusiasta": el poseído por la divinidad, como lo indica la etimología griega de la palabra (enthousiastếs), que se sabe irrevocablemente llamado a imponer la verdad trascendente y absoluta que le ha sido revelada. ${ }^{31}$

Su compleja construcción teórico-práctica de la soberanía política moderna es la respuesta a este desafío; en ella se plasma el intento de construir un orden social inmanente capaz de canalizar las energías humanas liberadas con el colapso del absolutismo del medioevo. Para lograrlo, la insociabilidad no ha de ser reprimida, sino más bien conservada, pero a la vez neutralizada en su dimensión cognitiva y política. Así, los entusiastas de la fe han de ser transformados en escépticos prácticos, a la manera de los científicos y demás expertos modernos, para quienes la verdad ha dejado de ser trascendente y total, pasando a ser inmanente - su validez controlada por los protocolos propios de una comunidad de pares-, relativa y falsable. Y la soberanía moderna se define por instaurar y dar protección a estos espacios; éstos, sustraídos de "la gue-

${ }^{30}$ Richard H. Popkin, The History of Scepticism: From Savonarola to Bayle (Oxford: Oxford University Press, 2003).

31 Thomas Hobbes, Leviathan: With Selected Variants from the Latin Edition of 1668, editado por Edwin Curley (Indianapolis, IND: Hackett Publishing Company, 1994), viii, 25; xii, 19; xxxii, 9. 
rra de todos contra todos" por un poder que monopoliza la violencia, hacen posible el formidable despliegue del poder de lo relativo que caracteriza al mundo moderno. ${ }^{32}$

Tales espacios no son ni podrían entonces ser ajenos a lo político, a la soberanía; no obstante, su politicidad está marcada por una paradoja constitutiva: existe en la precisa medida en que puede ser ignorada por quienes participan en ella. Y éste es el principio generador de la complejidad inherente a la polis moderna; de su diferenciación en esferas - tecnociencia, economía, arte, derecho, religión - regidas por principios de validez en principio independientes entre sí. En relación con ellas, la soberanía moderna habita el lugar intensa y explícitamente político de la excepción y de la paradójica y absoluta interdicción de lo absoluto en el espacio público y la consiguiente protección absoluta de lo relativo. Sin embargo, y a diferencia de lo que Carl Schmitt muy superficialmente extrajo de su lectura de Hobbes - y que hoy sus seguidores de izquierda y derecha repiten-, esa excepción nada tiene que ver con declarar el "estado de excepción". ${ }^{33}$ Pues declararlo, intentando sustituir el despliegue societal de lo relativo por el imperio sin mediación de lo absoluto, equivale a la renuncia a la altura de la soberanía, a su disolución en medio de un renovado estado de naturaleza.

32 Fundamental entre estos espacios es el mercado. Su principio, tal como lo observó Hayek, es ese formidable poder de lo relativo, en ausencia de toda inteligencia central. F. A. von Hayek, "The Use of Knowledge in Society". The American Economic Review 5, n. ${ }^{\circ} 4$ (1945): 519-530.

33 Ver para esto Eduardo Sabrovsky, "Carl Schmitt, enemigo de sí mismo", Revista de Filosofía Aurora 29, n. ${ }^{\circ} 47$ (mayo/agosto 2017): 551-574. En ese mismo texto se aborda la elocuente incomprensión de Schmitt de la cuestión de los milagros en Hobbes, en su Leviatán en la teoría del Estado de Thomas Hobbes. Pues, ante esta candente cuestión — la intromisión de lo absoluto en el espacio político reivindicada por los entusiastas - Hobbes responde estableciendo una distinción fundamental. Pues, afirma, sólo al soberano le cabe decidir sobre la ocurrencia efectiva de milagros; a la vez, si algún ciudadano opta por creer, al soberano no le cabe intervenir siempre que se trate de creencias mantenidas en la interioridad de la conciencia o, por qué no, de una comunidad de creyentes ("Of Miracles and Their Use”, en Leviathan:... editado por Edwin Curley, op. cit.: 293-300). Así, bajo la construcción hobbesiana de la soberanía, toda fe substantiva es neutralizada, transformada en mera creencia. Y el soberano no es ya una antena atenta a las comunicaciones venidas desde lo alto, sino una suerte de pararrayos que, en el improbable caso de que ocurriesen, las sepultaría en la tierra. Schmitt, al reducir este fundamental elemento de la arquitectura de la soberanía moderna a un resquicio a través del cual se habría de filtrar la sedición judía, lo malentiende radicalmente. 
Lo absoluto moderno, en cambio, vive de la invisibilidad que le otorga la paradoja que lo envuelve.

Con sus verdades y hechos alternativos, el populismo es la expresión política de la insociabilidad contemporánea. Estas nociones, que han comenzado a volverse recurrentes a raíz de eventos inesperados tales como el Brexit, la elección de Donald Trump o de Jair Bolsonaro, ponen en evidencia una situación en la cual progresivamente el conflicto político gira, no en torno a hechos y a su construcción e interpretación ideológica —una escena en la que diferentes ideologías compiten por la verdad-, sino que, más bien, a la verdad como tal. En otras palabras, el dispositivo de producción de la verdad pública que ha caracterizado al mundo moderno parece estar en retirada, dando paso a la fragmentación del nuevo "estado de naturaleza".

Lo que llamo aquí "dispositivo" es el complejo formado por instituciones del saber - universidades, think tanks-; por los diversos saberes y estamentos de especialistas, desde científicos, divulgadores, hasta los diversos consultores, asesores y expertos que, después de cursar estudios de tercer ciclo, salen a engrosar las filas de los organismos del Estado, de ONGs y empresas; finalmente, por los medios y la industria cultural. Y es la credibilidad pública de este complejo la que se encuentra en entredicho, en parte por su progresivo distanciamiento de la vida real del resto de la población, y en parte también como efecto de las tecnologías digitales -internet, las redes sociales, la economía de la atención, los macrodatos y la algoritmización - con su incremento del potencial de fragmentación inherente a la era moderna. Pero hay algo más en esta crisis de la verdad pública.

Pues estos estamentos de especialistas, y la misma población educada, ya hace tiempo han dejado de ver a través del tupido y paradójico velo de olvido con que la soberanía moderna, necesariamente como hemos visto, envuelve a su absoluto; la ficción de la apoliticidad, de la neutralidad de los saberes, ha pasado a constituir la garantía de cientificidad y verdad. Por eso, cuando esta ficción se ve confrontada a verdades alternativas - como el "creacionismo" opuesto a ciencia moderna, que las confesiones evangélicas de los Estados Unidos de Norteamérica expanden por el planeta-, el velo se descorre y deja ver un panorama inquietante.

Durante buena parte del siglo XX hasta el día de hoy, la cuestión de la verdad ha generado una división radical al interior de las comu- 
nidades del saber. Por un lado, en las disciplinas humanísticas y en parte de las ciencias sociales, y a partir de una lectura muy simplista de filósofos como Nietzsche o Jacques Derrida, el relativismo ha sido reconocido y celebrado: al fin, las malditas verdades absolutas han sido destronadas. Pero lo celebrado ha sido, más bien, la distancia respecto al absoluto de la soberanía moderna; en otras palabras, lo que causa regocijo es la discreta protección que el poder brinda a la discusión intelectual. Al otro lado de la línea se ubica la empresa globalizada de las ciencias "duras", empeñadas, según se suelen presentar, en revelar la estructura del mundo tal como es, sin más. Se trata, por cierto, de una promesa, de un horizonte; éste, sin embargo, suele ser invocado como legitimación no solamente de las ciencias, sino que también de la era moderna en cuanto tal. Pero este horizonte de verdad incondicional no podría ser el de las cosas en sí mismas, sino el del saber, no en cuanto mera contemplación sino, primordialmente, en cuanto poiésis, producción de su solo "objeto" y "referente" absoluto, el secularizado mundo moderno en cuanto tal. Es también, ya lo sabemos, el de la religión de la razón de Kant, en la cual se renovaba la fe, la fidelidad al proyecto moderno. En ausencia de esta religión, la pretendida incondicionalidad del saber moderno se convierte en un mero dogma revestido de un platonismo de segunda mano. ${ }^{34}$

Todo esto podría carecer de significación fuera de los claustros académicos y las discusiones eruditas. ¿Acaso la tecnociencia no funciona? ¿Qué importan entonces Platón o Kant, bien o mal leídos, cuando se trata de la vida cotidiana, de hacer compras en el mall, de pagar con dinero plástico o de subir fotografías a Facebook? La respuesta es que, efectivamente, no importan hasta que sucede algo inesperado. Y lo inesperado, que ahora sucede, es la emergencia del creacionismo. Pues sus defensores han advertido que la ciencia moderna no es resultado de una búsqueda incondicional de la verdad, sino que, como lo enseña por lo demás su historia, está inherentemente ligada al desencantamiento moderno de la naturaleza, del cual surge tanto el evolucionismo como

${ }^{34}$ Ya en los albores del mundo moderno, Descartes expresa su fundamentum inconcussum veritatis, su fundamento último e inconmovible de la verdad, en términos, no de intellectus, sino de cogito. Pues se trata entonces de un co-agitare (de agere: hacer, actuar). Es decir, de un hacer, un producir. Ver: Martin Heidegger, "Die Zeit des Weltbildes"; "Nietzsches Wort 'Gott ist Tot", en Holzwege (Frankfurt del Meno: Klostermann, 2003), 75-113; 209-267. 
la matematización de las ciencias. ${ }^{35}$ De aquí, los creacionistas concluyen que la ciencia moderna se fundamentaría en una mera mitología atea, cuya única superioridad respecto al creacionismo sería - descontando la fe de los creyentes en un Dios que habría creado el mundo hace sólo unos miles de años, y habría sembrado en él fósiles para engañar a los infieles - el poder del Estado moderno para imponerla.

Recapitulo: desde el Leviatán de Hobbes hasta La religión dentro de los límites de la mera razón de Kant, la era moderna ha estado marcada por tentativas de transmutar en sociabilidad la insociabilidad inscrita en su mismo núcleo de sentido; por abrir espacios al interior de los cuales sea posible inscribir la libertad de elección de la cual disfrutan los individuos modernos en un mundo de cosas, bajo una instancia moral inmanente, que tanto la idea kantiana de la disposición (Gesinnung) como la de amor al propio destino (amor fati) en Nietzsche articulan ejemplarmente. No obstante, el mismo progreso del mundo moderno termina por impedir estas complejas construcciones de la subjetividad; así, los modernos "hombres sin atributos", imposibilitados ya de apropiarse de sus circunstancias, quedan destinados al resentimiento y la ira. Finalmente, se trata de lo que he llamado "segunda edad de la ira", en la cual, tecnologías de la insociabilidad mediante, la ira y el resentimiento circulan y se potencian globalmente a tiempo completo, y el ya frágil dispositivo de producción de la verdad pública se ve enfrentado a una

${ }^{35}$ Alexandre Koyré, From the Closed World to the Infinite Universe (Radford: A\&D Publishing, 2015); Marcel Gauchet, Le desenchantement du monde (París: Gallimard Education, 2005); Hans Blumenberg, The Legitimacy of the Modern Age, traducción de Robert M. Wallace (Cambridge: The MIT Press, 1985). La teoría de la evolución, a la que el creacionismo se opone frontalmente, es la explicación de la vida a partir del postulado moderno, en cuanto tal indemostrable, del desencantamiento del mundo natural: no hay en él formas dadas de una vez para siempre, sino orden a partir del desorden constitutivo. Y dicho postulado rige también la moral y la política modernas, en tanto producciones inmanentes de la ciudad de los hombres, emancipadas ya de la tutela de la "ciudad de Dios". Ver para esto: Jacques Monod, El azar y la necesidad (Barcelona: Tusquets, 2002). En esta notable obra, el biólogo francés, Premio Nobel 1965, fue capaz de articular una exposición del "estado del arte" de la biología en la segunda mitad del siglo XX, con una lúcida y muy vigente reflexión acerca de la inseparabilidad de la ciencia moderna y el postulado moderno del desencantamiento del mundo, y la moral y la política de la era moderna. Al reconocer que se trata de un postulado indemostrable, incondicional, pero a la vez histórico, Monod evita el dogmatismo. 
avalancha de verdades y hechos alternativos. El populismo fascistoide de hoy se alimenta de estos factores, y los potencia a la vez.

El pensamiento liberal actual — para finalizar vuelvo a él— lleva la marca de las denegaciones de su politicidad que son parte ya de su larga historia. Así, le resulta casi imposible al intelectual liberal contemporáneo aparecer renegando del mayor y más visible logro de la civilización liberal: la cultura del consumo y las tecnologías de la insociabilidad. Pero obsérvese la paradoja: los mismos teóricos del liberalismo, que, en sus escritos, desestiman la cuestión de la insociabilidad como si se tratase de una queja de intelectuales desplazados y nostálgicos, suelen ser los primeros sobre los cuales la insociabilidad encarnada en las redes sociales se deja caer, bajo la forma de comentarios abusivos, calumnias, "troleos", funas. De esta manera, al final del camino, no nos espera un amable intelectual liberal que dice "dinero sín" o "dinero no", sino el vástago, monstruoso y no obstante legítimo del liberalismo, el mismísimo Donald Trump: You are fired!

\section{BIBLIOGRAFÍA}

Allison, Henry E. "Wille, Willkür, and Gesinnung". En Kant's Theory of Freedom, 129-145. Cambridge: Cambridge University Press, 1990.

Alter, Adam. Irresistible: The Rise of Addictive Technology and the Business of Keeping Us Hooked. Nueva York: Penguin Books, 2018.

Bernstein, Richard J. Radical Evil: A Philosophical Interrogation. Cambridge, MA: Polity, 2002.

Blumenberg, Hans. The Legitimacy of the Modern Age, traducción de Robert M. Wallace. Cambridge: The MIT Press, 1985.

Borges, Jorge Luis. "De las alegorías a las novelas". En Obras completas II 19521972, 122-124. Buenos Aires: Emecé, 2004.

Chapernel Elorduy, Eduardo. "Gesinnung y autoconocimiento en la filosofía de la religión kantiana". En Rostros de la razón: Immanuel Kant desde Hispanoamérica. Vol. III Filosofía de la religión, de la historia y crítica de la facultad de juzgar: Estética y teología, editado por Gustavo Leyva. Barcelona - Ciudad de México: Anthropos, 2014.

Crosby, Alfred W. The Measure of Reality: Quantification and Western Society, 1250-1600. Cambridge: Cambridge University Press, 1997.

Gauchet, Marcel. Le desenchantement du monde. París: Gallimard Education, 2005.

Hayek, F. A. von. "The Use of Knowledge in Society". The American Economic Review 5, n. ${ }^{\circ} 4$ (1945): 519-530. 
Heidegger, Martin. "Die Zeit des Weltbildes"; "Nietzsches Wort 'Gott ist Tot"”. En Holzwege. Frankfurt del Meno: Klostermann, 2003.

Hobbes, Thomas. Leviathan: With Selected Variants from the Latin Edition of 1668, editado por Edwin Curley. Indianapolis, IND: Hackett Publishing Company, 1994.

Kant, Immanuel. Crítica de la facultad de juzgar. Caracas: Monte Ávila Editores, $\mathrm{s} / \mathrm{f}$.

Idea para una historia universal en clave cosmopolita. México DF: UNAM, 2006.

La religión dentro de los límites de la mera razón. Madrid: Alianza, 2009.

Koyré, Alexandre. From the Closed World to the Infinite Universe. Radford: A\&D Publishing, 2015.

Latour, Bruno. Down to Earth: Politics in the New Climatic Regime. Cambridge, UK; Medford, MA: Polity, 2018.

Mishra, Pankaj. La edad de la ira. Barcelona: Galaxia Gutenberg, 2017.

Monod, Jacques. El azar y la necesidad. Barcelona: Tusquets, 2002.

Muller, Jerry Z. The Tyranny of Metrics. Princeton: Princeton University Press, 2018.

Musil, Robert. Der Mann Ohne Eigenschaften. Hamburgo: Rowohlt Verlag, 1952.

Nietzsche, Friedrich. Ecce homo: Cómo se llega a ser lo que se es. Madrid: Alianza Editorial, 2013.

—. La genealogía de la moral. Un escrito polémico. Madrid: Alianza, 2013.

Oksenberg Rorty, Amélie \& James Schmidt, Eds. Kant's Idea for a Universal History with a Cosmopolitan Aim: A Critical Guide. Cambridge, New York, Melbourne: Cambridge University Press, 2012.

Peña, Carlos. Lo que el dinero sí puede comprar. Santiago: Taurus, 2017.

Popkin, Richard H. The History of Scepticism: From Savonarola to Bayle. Oxford: Oxford University Press, 2003.

Sabrovsky, Eduardo. "Carl Schmitt, enemigo de sí mismo". Revista de Filosofía Aurora 29, n. ${ }^{\circ} 47$ (mayo/agosto 2017): 551-574.

Sandel, Michael J. What Money Can't Buy: The Moral Limits of Markets. Nueva York: Farrar, Straus and Giroux, 2013.

Simmel, Georg. Filosofía del dinero. Madrid: Universidad Autónoma de México, 2013.

Trentmann, Frank. Empire of Things: How We Became a World of Consumers, from the Fifteenth Century to the Twenty-First. Nueva York: Harper, 2016.

Vaihinger, Hans. Die Philosophie des Als Ob: System der theoretischen, praktischen und religiösen Fiktionen der Menschheit auf Grund eines idealistischen Positivismus, editado por Alfred Schilken. CreateSpace Independent Publishing Platform, 2014.

Wu, Tim. The Attention Merchants: The Epic Scramble to Get Inside Our Heads. Nueva York: Vintage, 2016. EP 